\title{
Mineralization of Chitosan Membrane Using a Double Diffusion System for Bone Related Applications
}

\author{
S. Gomes ${ }^{1,2, a}$, M-E. Boulon ${ }^{1,2 b}$, A. L. Oliveira ${ }^{1,2 c}$, I. B. Leonor ${ }^{1,2 d}$, \\ J. F. Mano ${ }^{1,2 e}$, R. L. Reis ${ }^{1,2 f}$ \\ 13B's Research Group - Biomaterials, Biodegradables and Biomimetics, Dept. of Polymer \\ Engineering, Univ. of Minho, Campus de Gualtar, 4710-057 Braga, Portugal, www.3bs.uminho.pt \\ ${ }^{2}$ IBB - Institute for Biotechnology and Bioengineering, PT Government Associated Laboratory, \\ Braga, Portugal \\ asilvia.gomes@dep.uminho.pt, ${ }^{\mathrm{b}}$ marieemmanuelle@tele2.fr, ${ }^{\mathrm{c}}$ analeite@dep.uminho.pt, \\ dbelinha@dep.uminho.pt, ${ }^{\mathrm{d}} \mathrm{jmano@dep.uminho.pt,}{ }^{\mathrm{f}} \mathrm{rg}$ reis@dep.uminho.pt
}

Keywords: chitosan membranes, calcium-phosphate coating, double diffusion system

\begin{abstract}
Chitosan membranes were subjected to a pre-treatment in a double diffusion system, with a calcium solution in one chamber and a phosphate solution in the other chamber. Both chambers were separated by the chitosan membrane and subject to three mineralization periods $(5,10$ and 15 minutes). After this pre-treatment the bioactivity of the different calcium phosphate coatings formed was tested for different periods of immersion time, 7,14 and 21 days at room temperature and $37^{\circ} \mathrm{C}$, in acellular simulated body fluid (1.0x). The results obtained demonstrated that the calcium phosphate coatings formed during the pre-treatment process are bioactive. It was found that the calcification is effective just in the side of the membrane exposed to the calcium solution chamber. This enabled to develop membranes with asymmetric osteoinductive properties that can be useful in different orthopedic applications.
\end{abstract}

\section{Introduction}

Chitosan is a natural biopolymer with a potential application in the tissue engineering and drug delivery fields, composed by (1-4)-linked D-glucosamine and $N$-acetyl-D-glucosamine. This biopolymer is obtained through the deacetylation of chitin, one of the most abundant naturally occurring polysaccharides and a waste material of the seafood industry. The major difference between chitin and chitosan is that the former is formed by 2-acetamido-2-deoxy-D-glucose units while chitosan primary unit is 2-amino-2-deoxy-D-glucose, with $\beta, 1-4$ glucosidic linkages [1]. Chitosan is insoluble in water, alkali solutions and most organic solvents, however it can be diluted in organic acid solutions, such as acetic acid [2].

From the bio-functional point of view chitosan presents a unique set of properties, such as biocompatibility, biodegradability, to harmless products, and non-toxicity. Different chitosan-based biomaterials have been developed recently for biomedical application. These biomaterials include scaffolds [3], nanocomposites [4], microspheres [5], coatings [6], wound dessing [7] and membranes [8]. The combination of chitosan and calcium phosphates, especially hydroxyapatite, constitutes an excellent choice for bone repair and regeneration applications. The following study describes the use of chitosan membranes as a template for the mineralization of calcium phosphate (Ca-P) film using a double diffusion system, as a new tool to induce the apatite formation.

\section{Materials and Methods}

Chitosan (medium molecular weight and $6.6 \%$ of acetylation), calcium chloride, ammonium dihydrogen phosphate, acetic acid and sodium hydroxide were obtained from Sigma-Aldrich, Germany.

Chitosan membranes were prepared from a chitosan solution with a $2 \%(\mathrm{w} / \mathrm{v})$ concentration, 
obtained from the dissolution of chitosan in a $1 \%$ acetic acid solution. The mixture was stirred during two days at room temperature and filtered to remove impurities. The final solution was cast in a mold and left to dry at room temperature. Finally, the prepared membranes were treated for 10 minutes with a $1 \%$ sodium hydroxide solution, to neutralize the acetate groups, washed several times with distilled water, until neutral $\mathrm{pH}$ was reached, and left to dry at room temperature.

The mineralization process was carried out using a double diffusion system, at room temperature and under stirring. This system contains two chambers separated by a circular hole at the centre, where the chitosan membrane is fixed, preventing the contact of the two different solutions present in the respective chambers. Solutions of $10 \mathrm{mM}$ calcium chloride and $10 \mathrm{mM}$ of dihydrogen phosphate were prepared and $85 \mathrm{ml}$ of each solution were used to fill the two chambers. The solutions diffused through the chitosan membranes under different periods of time: 5 , 10, and 15 minutes. Afterwards, the chitosan membranes were immersed in acellular simulated body fluid (SBF) (1.0x) with ion concentration nearly equal to those of the human blood plasma in order to test

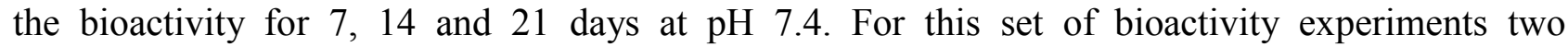
temperatures were tested, $37^{\circ} \mathrm{C}$ and room temperature.

The morphology of the Ca-P coatings on the chitosan membranes was characterized using a Scanning Electron Microscope (SEM, Leica-Cambridge S360-SEM) with an attached Energy Dispersive Spectroscopy (EDS, Oxford-Link eXLII) analyzer. The samples were coated with gold in an argon atmosphere for morphological analysis and coated with carbon for elemental characterization.

The mineralized membranes were also characterized by Attenuated Total Reflectance-Fourier Transform Infrared (ATR-FTIR, Shimadzu-IR Prestige 21 FTIR spectrophotometer) in order to evaluate the chemical structure.

\section{Results and discussion}

The results from the EDS analysis are showed in the Table 1. This analysis indicated the presence of calcium and phosphate elements in the membrane side which was exposed to the calcium solution in the double diffusion system (treatments 1, 2 and 3). Similar results were obtained for the treatments 4, 5, 7, 8, 11, 13, 17 and 20, after the subsequent immersion in SBF (1.0x) (Table 1). For the remaining treatments, $6,9,10,12,14,15,16,18,19$ and 21 , after the subsequent immersion in SBF (1.0x), it was detected the presence of the elements calcium and phosphorous on both sides of the chitosan membranes, exposed to calcium solution and to phosphorous solution in the double diffusion system (Table 1).

The morphology of the Ca-P coatings obtained in the different conditions is shown in the Fig. 1. It can be observed that when the membranes were exposed in the double diffusion chamber for 5, 10 and 15, there was the formation of Ca-P coating on the chitosan membrane, although only on the side that was exposed to the calcium solution (see the Fig.1 B-D). This could be explained by the fact that, the cationic nature of chitosan prevents the diffusion of the calcium ions through the chitosan membrane to the phosphorous side.

The bioactivity tests showed that after different immersion periods in SBF solution it was clear the bioactive nature of the Ca-P coatings (see the Fig. 1 E-J). The Ca-P film becomes more compact and dense as they gradually grow. At higher magnifications it was possible to observe the morphology of this film that evidenced a fine structure, where the needle loke crystals are agglomerated to produce the so called cauliflower like morphology, as it is shown in the Fig. 1 (EJ).

The SEM observations suggest that there were no differences in the morphologies of the Ca-P formed on the surface of the chitosan membrane when using two temperatures, $37^{\circ} \mathrm{C}$ and room temperature. 
Table 1. Elemental composition of the chitosan membranes subjected to different mineralization periods.

\begin{tabular}{ccccc}
\hline \multirow{2}{*}{$\begin{array}{c}\text { Treatment } \\
\text { identification }\end{array}$} & $\begin{array}{c}\text { Double diffusion } \\
\text { treatment }\end{array}$ & $\begin{array}{c}\text { SBF } \\
\text { treatment }\end{array}$ & $\begin{array}{c}\text { Ea sol. } \\
\text { side }\end{array}$ & P sol. side \\
\hline 1 & 5 minutes & - & $\mathrm{Ca}, \mathrm{P}$ & No elements \\
2 & 10 minutes & - & $\mathrm{Ca}, \mathrm{P}$ & No elements \\
3 & 15 minutes & - & $\mathrm{Ca}, \mathrm{P}$ & No elements \\
\hline 4 & 5 minutes & 7 days $/$ room temperature & $\mathrm{Ca}, \mathrm{P}$ & No elements \\
5 & 10 minutes & 7 days $/$ room temperature & $\mathrm{Ca}, \mathrm{P}$ & No elements \\
6 & 15 minutes & 7 days $/$ room temperature & $\mathrm{Ca}, \mathrm{P}$ & $\mathrm{Ca}, \mathrm{P}$ \\
7 & 5 minutes & 7 days $/ 37^{\circ} \mathrm{C}$ & $\mathrm{Ca}, \mathrm{P}$ & No elements \\
8 & 10 minutes & 7 days $/ 37^{\circ} \mathrm{C}$ & $\mathrm{Ca}, \mathrm{P}$ & No elements \\
9 & 15 minutes & 7 days $/ 37^{\circ} \mathrm{C}$ & $\mathrm{Ca}, \mathrm{P}$ & $\mathrm{Ca}, \mathrm{P}$ \\
\hline 10 & 5 minutes & 14 days $/$ room temperature & $\mathrm{Ca}, \mathrm{P}$ & $\mathrm{Ca}, \mathrm{P}$ \\
11 & 10 minutes & 14 days $/$ room temperature & $\mathrm{Ca}, \mathrm{P}$ & No elements \\
12 & 15 minutes & 14 days $/$ room temperature & $\mathrm{Ca}, \mathrm{P}$ & $\mathrm{Ca}, \mathrm{P}$ \\
13 & 5 minutes & 14 days $/ 37^{\circ} \mathrm{C}$ & $\mathrm{Ca}, \mathrm{P}$ & No elements \\
14 & 10 minutes & 14 days $/ 37^{\circ} \mathrm{C}$ & $\mathrm{Ca}, \mathrm{P}$ & $\mathrm{Ca}, \mathrm{P}$ \\
15 & 15 minutes & 14 days $/ 37^{\circ} \mathrm{C}$ & $\mathrm{Ca}, \mathrm{P}$ & $\mathrm{Ca}, \mathrm{P}$ \\
\hline 16 & 5 minutes & 21 days $/$ room temperature & $\mathrm{Ca}, \mathrm{P}$ & $\mathrm{Ca}, \mathrm{P}$ \\
17 & 10 minutes & 21 days $/$ room temperature & $\mathrm{Ca}, \mathrm{P}$ & No elements \\
18 & 15 minutes & 21 days $/$ room temperature & $\mathrm{Ca}, \mathrm{P}$ & $\mathrm{Ca}, \mathrm{P}$ \\
19 & 5 minutes & 21 days $/ 37^{\circ} \mathrm{C}$ & $\mathrm{Ca}, \mathrm{P}$ & $\mathrm{Ca}, \mathrm{P}$ \\
20 & 10 minutes & 21 days $/ 37^{\circ} \mathrm{C}$ & $\mathrm{Ca}, \mathrm{P}$ & $\mathrm{No}$ elements \\
21 & 15 minutes & 21 days $/ 37^{\circ} \mathrm{C}$ & $\mathrm{Ca}, \mathrm{P}$ & $\mathrm{Ca}, \mathrm{P}$ \\
\hline
\end{tabular}

In the Fig. 2 it is shown the FT-IR spectra of the surface of the chitosan membranes, which were subject to the double diffusion treatment and the subsequent immersion in $\mathrm{SBF}$ for 7 days, at $37^{\circ} \mathrm{C}$ and room temperature. This analysis was only performed for the membranes that were exposed to the calcium solution, after immersion in SBF, because according with the SEM analysis, the calcium phosphate coating was only formed in this side of the chitosan membrane. There were no significant differences between the several immersion times in SBF (data not shown).

In the spectra for both temperatures, the transmittance band around $1010 \mathrm{~cm}^{-1}$, correspond to the stretching and bending vibrations of $\mathrm{PO}_{4}{ }^{3-}$. The broad band appearing in the region of 3300$3500 \mathrm{~cm}^{-1}$ is assigned to the vibrational band of $\mathrm{HO}^{-}$groups characteristic of apatite or in general can be assigned to the absorbed water or moisture in the samples [3].

The peaks for carbon-oxygen, carbon-hydrogen and amide, characteristic of chitosan, are also present in both spectra. The peaks at $1340 \mathrm{~cm}^{-1}$ and $1660 \mathrm{~cm}^{-1}$ are assigned to the amide I carbonyl stretch and the band in the region of $2960-2800 \mathrm{~cm}^{-1}$, is attributed to the $-\mathrm{CH}_{2}$ of this polymer.

The peak at $1660 \mathrm{~cm}^{-1}$ decreased, when compared with the untreated sample (a), due to the formation of Ca-P coating which result in the interaction of the amines, present in chitosan [9]. The band between the 1240 and $1400 \mathrm{~cm}^{-1}$ results from the $\mathrm{C}-\mathrm{O}$ stretching vibrations. 


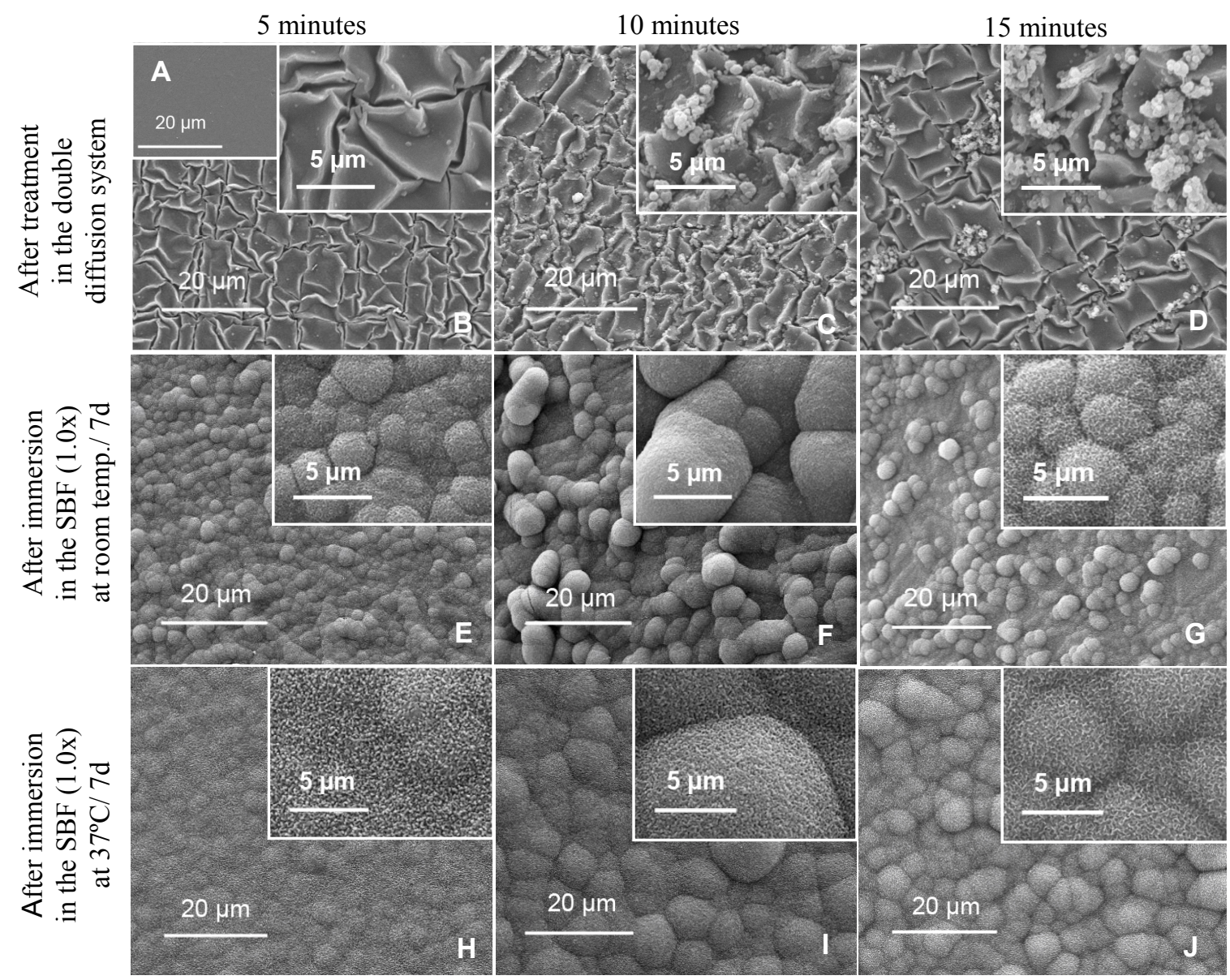

Figure 1 SEM micrographs of the Ca-P coatings after the treatment of the chitosan membranes in the double diffusion chamber and the subsequent immersion in the SBF. (A) Chitosan membrane, untreated (control).
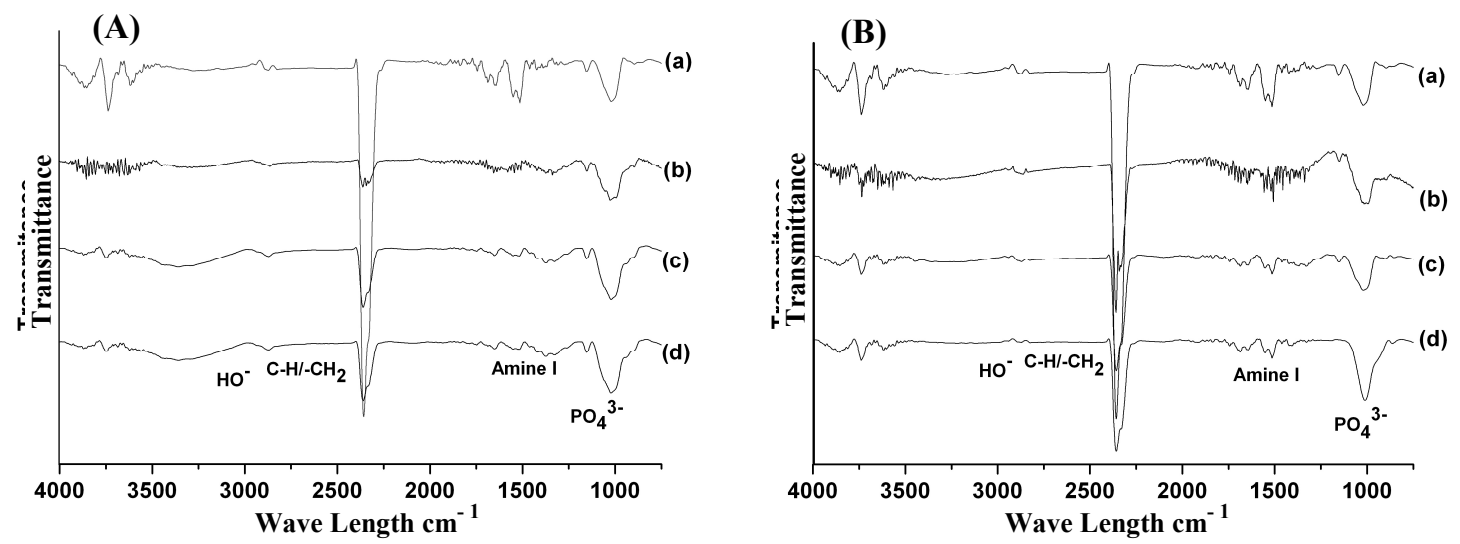

Figure 2 FT-IR spectra to the chitosan membranes subjected to a 5 (b), 10 (c) and 15 minutes (d) pre-treatment in the double diffusion system and with posterior immersion in SBF (1.0x) for 7 days, at room temperature (A) and at $37^{\circ} \mathrm{C}(\mathrm{B})$. (a) Chitosan membrane, untreated (control). 


\section{Conclusions}

The results obtained, demonstrate that, by using this new approach, a pretreatment of the chitosan membranes in the double diffusion system followed by their immersion in SBF (1.0x), it was possible to induce the formation of a Ca-P film on the membrane side exposed to the Ca solution. It is worth notice that chitosan is not bioactive by it self. Moreover, this system can be considered as a fast mineralization tool to induce the deposition of an apatite like layer in only one side of the chitosan membrane. This type of polymer can be considered as a promising material for small repairs at the surface of bone, where the mineralized side of the membrane is in contact with the bone injury and the non mineralized side is in contact with the surrounding environment.

\section{Acknowledgments}

This work was partially founded by the European Union funded STREP Project HIPPOCRATES (NMP3-CT-2003-505758), the European NoE EXPERTISSUES (NMP3-CT-2004-500283) and the INTERREG III A Project SP1.P151/03, PROTEUS.

\section{References}

[1] H. Ehrlich, B. Krajewska, T. Hanke, R. Born, S. Heinemann, C. Knieb, H. Worch: J. Membr. Sci. Vol. 273 (2006) p. 124.

[2] I. Manjubala, S. Scheler, Jörg Bössert, Klaus D. Jandt: Acta Biomaterialia Vol. 2 (2006) p.75.

[3] W. Tachaboonyakiat, T. Derizawa, M. Akashi: J. Biomater. Sci. Polymer Ed. Vol 13 (2002), p. 1021.

[4] Z. Li, L. Yubao, Y. Aiping, P. Xuelin, W. Xuejiang, Z. Xiang: J. Mater. Sci. Mater. Med. Vol. 16 (2005) p. 213.

[5] H. M. Song, R.P. Nacamuli, T.D. Fang, M.T. Longaker: J. Craniofac. Surg. Vol. 15 (2004) p. 312

[6] J.D. Baumgardner, R. wiser, P.D. Gerard, P. Bergin, B. Chestnutt, M. Marini, V. Ramsey, S.H. Elder, J.A. Gilbert: J. Biomater. Sci. Vol. 14 (2003) p. 423.

[7] W. Paul, C.P. Sharma: Trends Biomater. Artif. Organs Vol. 18 (2004) p. 18.

[8] M.M. Beppu, C.C. Santane: Mater. Sci. Eng. C Vol. 23 (2003) p. 651.

[9] Z.K. Jonathan, M.H. Samuel, A.C. Katherine: J. Appl. Polym. Sci. Vol. 72 (1999) p.1721. 